\title{
EFEKTIVITAS PENGGUNAAN DIGITAL STORYTELLING KANAL YOUTUBE "Ilmu Komunikasi UNJ" DALAM MENINGKATKAN KETERAMPILAN KOMUNIKASI
}

\author{
Yosua Novry Susilo \\ yosuanovry@gmail.com \\ Program Studi IlmuKomunikasi, Universitas Negeri Jakarta, \\ Jl. RawamangunMuka RT.11/RW.14, Rawamangun, PuloGadung, \\ Kota Jakarta Timur, DKI Jakarta, 13220, Indonesia. \\ Submitted: 29 Juni 2020| Accepted: 24 September 2020 | Published: 30 \\ Desember 2020 \\ Website: https://e-journal.umc.ac.id/index.php/jike/index
}

\begin{abstract}
The development of technology facilitates human work, one of which is digital media education. Digital storytelling is a digital story that is built from narratives about internet culture (cyberculture). Communication skills are a person's knowledge of techniques to convey messages clearly and are able to solve a problem or conflict properly The purpose of this study is to explain how effective the use of YouTube digital storytelling in providing education about communication and improving communication skills of subscribers or viewers. This research uses a quantitative method with a positivism paradigm. Samples were taken by simple random sampling technique on 50 respondents namely YouTube channel subscriber "Communication Studies UNJ". The results of the correlation analysis research with the results of 0.727 included in the strong category. Furthermore, this research $\mathrm{HO}$ was rejected and $\mathrm{H} 1$ was accepted because tcount $(7,342)>$ ttable $(1,660)$ meant the use of digital storytelling in improving effective communication skills. The use of digital storytelling also had an effect on the audience by 52.9\% to improve communication skills and $47.1 \%$ influenced by other factors. Keywords: Communication Skills; Digital Storytelling; “Ilmu Komunikasi UNJ”; New Media; Youtube
\end{abstract}

\begin{abstract}
Abstrak
Perkembangan teknologi memudahkan pekerjaan manusia, salah satunya edukasi media digital. Digital storytelling merupakan cerita digital yang dibangun dari narasi perihal budaya internet (cyberculture). Keterampilan komunikasi merupakan pengetahuan seseorang akan teknik untuk menyampaikan pesan secara jelas dan mampu memecahkan suatu masalah atau konflik dengan baik Tujuan penelitian ini adalah menjelaskan seberapa efektif penggunaan digital storytelling youtube dalam memberikan edukasi mengenai komunikasi dan meningkatkan keterampilan komunikasi subscriber atau penontonnya. Penelitian ini menggunakan metode kuantitatif dengan paradigma positivisme. Sampel diambil dengan teknik simple random sampling pada 50 responden yaitu subscriber kanal youtube "Ilmu Komunikasi UNJ". Hasil penelitian analisis korelasi dengan hasil sebesar 0,727 termasuk pada kategori kuat. Selanjutnya penelitian ini H0 ditolak dan H1 diterima karena thitung $(7.342)>$ ttabel $(1,660)$ artinya penggunaan digital storytelling dalam meningkatkan keterampilan komunikasi efektif. Penggunaan digital storytelling juga memberikan pengaruh pada penonton sebesar 52,9\% terhadap meningkatkan keterampilan komunikasi dan 47,1\% dipengaruhi oleh faktor-faktor lain. Keywords: Digital storytelling; “Ilmu Komunikasi UNJ”; Keterampilan Komunikasi; New Media; Youtube
\end{abstract}

\section{A. PENDAHULUAN}

Komunikasi merupakan salah satu hal yang sangat penting dalam kelangsungan hidup manusia dan kehidupan bangsa. Komunikasi yang efektif dapat memberikan banyak dampak positif dalam kehidupan individu maupun kehidupan bernegara. Komunikasi menurut (Nurudin, 2016, p. 118), adalah suatu usaha untuk menyampaikan gagasan dan mendapatkan umpan balik atau feedback dari gagasan yang disampaikan. Salah satu 
faktor yang berpengaruh dalam komunikasi adalah kemampuan dalam hal pengetahuan dan membaca lawan bicara atau komunikan. Perkembangan zaman menghadirkan era digital yang memberikan banyak manfaat dalam hal informasi dan berkomunikasi, karena media baru (new media) sudah menjadi kebutuhan sehari-hari yang harus dipenuhi. Hadirnya media baru sangat mempermudah akses informasi, hiburan, dan pendidikan.

Salah satu hasil yang didapat dari hadirnya media baru adalah interconnection network atau disingkat dengan internet. Menurut (Ahmadi\&Hermawan, 2013, p. 68), internet merupakan jaringan komunikasi global yang menghubungkan teknologi yang ada seperti komputer, ponsel, dan media lainnya. Berdasarkan data statistik pada Januari 2019 dari Kementrian Komunikasi dan Informasi Republik Indonesia, pengguna internet telah mencapai 150 juta jiwa dengan penetrasi 56\% yang tersebar di seluruh wilayah (https://aptika.kominfo.go.id/2019/08/penggunaan-internet-di-indonesia/, 2019) (diakses pada 22 Mei 2020). Banyaknya pengguna internet di Indonesia merupakan faktor dari adanya infrastruktur di dalam peningkatan jaringan bernama fiber optic yang menjadi sumber dalam mengakses internet.

Interconnection network memang sudah terbukti dalam meningkatkan kualitas manusia dan bangsa. Hal itu dapat terjadi karena internet memudahkan dalam mengakses informasi, hiburan dan pendidikan. Salah satu contohnya adalah aplikasi Youtube. Youtube merupakan suatu aplikasi yang memungkinkan penggunanya untuk menciptakan dan melihat video-video referensi. Content creator merupakan sebutan dari pencipta video yang ada di aplikasi Youtube. Ide-ide kreatif serta editing yang sempurna menjadi daya tarik yang besar bagi pengguna lain yang melihat. Pada penelitian ini, penulis memiliki fokus pada kanal edukasi dalam berkomunikasi karena masih banyak fenomena kurangnya efektivitas komunikasi pada masyarakat. "Ilmu Komunikasi UNJ" merupakan kanal edukasi Youtube yang memberikan pengetahuan akan komunikasi berbasis videografis, infografis dan storytelling.

"Ilmu Komunikasi UNJ" merupakan kanal edukasi yang dibentuk oleh para dosen dan mahasiswa Universitas Negeri Jakarta (UNJ) program studi Ilmu Komunikasi untuk menyebarkan pengetahuan akan berkomunikasi sekaligus menyebarkan informasi mengenai program studi Ilmu Komunikasi UNJ. Konten edukasi yang dikemas dengan videografis bertujuan untuk memberikan pemahaman informasi yang jelas. Kanal "Ilmu Komunikasi UNJ" memberikan banyak pengetahuan mengenai sejarah komunikasi, teori komunikasi, cara berkomunikasi, efektivitas komunikasi, dan lain-lain. Youtube ini juga bertujuan untuk 
meningkatkan literasi dengan menghadirkan konten-konten edukasi. Pembuatan video berbasis storytelling bertujuan agar penonton tertarik akan informasi yang diberikan dan menghasilkan stimulus untuk menggali lebih dalam mengenai informasi serta menambah literasi. Saat ini, "Ilmu Komunikasi UNJ" memiliki 281 subscribers, 54 video dan total penonton sekitar 5000 .

Pemanfaatan komunikasi visual menjadi salah satu komponen penting untuk menciptakan konten di Youtube. Desain komunikasi visual juga merupakan faktor yang mempengaruhi ketertarikan penonton atau subscriber. Menurut (Supriyono, 2010, hal. 9), desain komunikasi visual merupakan proses komunikasi menggunakan panca indera yang diaplikasikan kedalam media visual seperti tipografi, ilustrasi warna, garis, layout dan sebagainya dengan bantuan teknologi. Komunikasi visual merupakan alat yang digunakan untuk menyampaikan informasi yang berbentuk unsur rupa atau visual seperti televisi, video, internet, dan lain sebagainya.

Efektivitas menunjukan proses suatu tujuan yang ingin dicapai, dengan kata lain efektivitas artinya sejauh mana tujuan telah terpenuhi sesuai harapan. Menurut Moore D. Kenneth dalam (Sumantri, 2015, hal. 1), efektivitas merupakan suatu ukuran untuk menilai seberapa jauh tujuan telah tercapai, semakin besar presentase target yang dicapai maka semakin tinggi efektivitasnya.

Perkembangan zaman khususnya teknologi digital memunculkan terobosan baru di dalam dunia pendidikan salah satunya adalah digital storytelling. Digital storytelling merupakan cerita digital yang dibangun dari narasi perihal budaya internet (cyberculture) (Alexander, 2011, hal. 3). Narasi atau cerita yang dibentuk memanfaatkan multimedia (gambar, video, grafik digital, teks, musik) untuk memaparkan suatu materi yang dikemas dengan format digital. Media digital storytelling memilikki kelebihan untuk meningkatkan minat belajar dan meningkatkan motivasi dalam belajar (Heriyana, 2014). Dalam penelitian ini, media digital storytelling mempunyai manfaat dalam meningkatkan minat dan motivasi seseorang dalam belajar keterampilan komunikasi. Lambert, dalam bukunya memaparkan 7 elemen yang efisien dalam digital storytelling (Lambert, 2010, hal. 9-19), yaitu:

1) Point of View

Point of View atau sudut pandang merupakan komunikasi antara penonton dengan materi yang disampaikan.

2) Dramatic Question

Sebuah pertanyaan untuk menarik keingintahuan penonton. 


\section{3) Emotional content}

Menarik atau melibatkan perasaan penonton.

4) The gift of your voice

Efek narasi yang berbentuk suara untuk memberikan pemahaman yang jelas bagi penonton.

5) Soundtrack

Penambahan suara dan musik untuk meningkatkan respon emosional penonton.

6) Economy

Pemberdayaan pembawaan materi untuk meningkatkan efektivitas penjelasan materi agar penonton tidak bosan.

7) Pacing

Pacing atau irama cerita yang menentukan kecepatan pemaparan dalam bercerita.

Keterampilan komunikasi merupakan pengetahuan seseorang akan teknik untuk menyampaikan pesan secara jelas dan mampu memecahkan suatu masalah atau konflik dengan baik (Dalimunthe, 2008) Keterampilan komunikasi dibagi menjadi tiga macam bentuk, yaitu: (1) Keterampilan komunikasi lisan, merupakan kemampuan seseorang dalam berbicara dengan baik seperti presentasi, berpidato, dan lain-lain; (2) Keterampilan komunikasi tulisan, merupakan kemampuan seseorang dalam menulis dan memberikan pesan-pesan secara tertulis dengan baik seperti proposal, surat, laporan, dan lain-lain; (3) Keterampilan komunikasi visual menurut (Supriyono, 2010, hal. 9), merupakan kemampuan seseorang dalam mengkomunikasikan pesan melalui bentuk-bentuk visual seperti desain grafis, seni rupa, dan lain-lain.

\section{B. Tinjauan Pustaka}

\section{Efektivitas Penggunaan Digital Storytelling Kanal Youtube "Kok Bisa?" Dalam Meningkatkan Minat Belajar}

Penelitian sejenis ini pernah dilakukan oleh Hikmad Drajat \& Hadi Purnama (2019) dalam Jurnal Komunikasi Universitas Garut: Hasil Pemikiran dan Penelitian 6 (1), 383-390 mengenai digital storytelling, dan pengaruh kanal youtube "Kok Bisa?" dalam meningkatkan minat belajar. Penelitian ini bertujuan untuk menjelaskan efektivitas penyampaian informasi yang dilakukan kanal "Kok Bisa?" dalam memberikan edukasi 
dengan media animasi dan digital. Penelitian menggunakan metode survey dengan pendekatan kuantitatif. Teknik pengambilan sampel menggunakan simple random sampling dengan 100 responden subscribers kanal youtube "Kok Bisa?". Hasil penelitian ini adalah regresi linier sederhana sebesar $\mathrm{Y}=-2,166+0,466 \mathrm{X}$, analisis korelasi 0,683 yang termasuk pada kategori kuat, selanjutnya efektivitas penggunaan digital storytelling terhadap meningkatkan minat belajar memiliki pengaruh, serta penggunaan digital storytelling memilikki pengaruh sebesar $46,6 \%$ dan sisanya berasal dari faktor-faktor lain.

\section{Metode Penelitian}

Penelitian ini menggunakan metode survey dengan pendekatan kuantitatif. Penelitian kuantitatif (Quantitative Research), merupakan metode penelitian yang berkaitan erat dengan teknik survey sosial untuk menggambarkan dan menguji hipotesis yang telah ditetapkan seperti kuesioner, observasi, analisis statistik, dan lain-lain (Sutama, 2016, hal. 43). Paradigma dalam penelitian menggunakan paham positivisme yang meyakini bahwa suatu masalah dapat dipecahkan dengan angka dan bersifat kausal (sebab-akibat).

Target populasi pada penelitian ini adalah subscribers dari akun Youtube "Ilmu Komunikasi UNJ" yang pada saat ini memilikki jumlah 288 subscribers. Teknik pengambilan sampel pada penelitian ini adalah simple random sampling yang bertujuan untuk mengambil sampel secara acak tanpa hambatan dan memberikan kesempatan pada subscribers "Ilmu Komunikasi UNJ" untuk menjadi sampel pada penelitian ini.

\section{Hasil dan Pembahasan}


Tujuan dari penelitian ini adalah menganalisis efektivitas penggunaan digital storytelling pada kanal youtube "Ilmu Komunikasi UNJ" dalam meningkatkan keterampilan komunikasi penonton atau subscribers. Responden yang diteliti sebanyak 50 responden, dengan responden perempuan sebanyak $33(66 \%)$ dan responden laki-laki sebanyak 17 (34\%). Usia responden yang diteliti sebesar 94\% berusia 17-20 Tahun, dan 6\% berusia 2124 Tahun. Dari lima sub variabel yang diatas, persentase sub variabel pemberian suara tertinggi yaitu 83,90\%, hal ini mengartikan bahwa sebagian besar subscriber menyukai konten "Ilmu Komunikasi UNJ". Sedangkan yang paling rendah adalah sub variabel empati yaitu sebesar 63,30\%, hal ini menunjukkan bahwa kanal Youtube "Ilmu Komunikasi UNJ" tidak menanggapi komentar subscriber dengan cepat dan tidak menjawab secara tepat maksud dari komentar subscriber.

Secara keseluruhan tanggapan responden pada variabel ini sebesar 78,44\% untuk 13 butir pertanyaan yang termasuk kedalam kategori tinggi yang memiliki arti bahwa rata-rata subscriber pada kanal youtube "Ilmu Komunikasi UNJ" menyukai konten, memiliki keingintahuan yang tinggi, dan aktivitas belajar yang baik.

\section{Uji Normalitas}

Berdasarkan data yang diperoleh melalui google form, maka dapat dilakukan uji normalitas untuk mengetahui apakah data berdistribusi dengan normal. Hasil pengolahan data melalui program SPSS 18 adalah sebagai berikut:

Tabel 1

One-Sample Kolmogorov-Smirnov Test

\begin{tabular}{|c|c|c|}
\hline & & $\begin{array}{c}\text { Unstandardized } \\
\text { Residual }\end{array}$ \\
\hline $\mathrm{N}$ & & 50 \\
\hline \multirow[t]{2}{*}{ Normal Parameters ${ }^{a, b}$} & Mean & .0000000 \\
\hline & Std. Deviation & 3.37996915 \\
\hline \multirow[t]{3}{*}{ Most Extreme Differences } & Absolute & .092 \\
\hline & Positive & .092 \\
\hline & Negative & -.091 \\
\hline Kolmogorov-Smirnov Z & & .648 \\
\hline Asymp. Sig. (2-tailed) & & .795 \\
\hline
\end{tabular}
a. Test distribution is Normal.
b. Calculated from data. 
Berdasarkan tabel uji normalitas Kolmogorov-Smirnov, data memiliki nilai Asymp. Sig. (2-tailed) sebesar 0,795 dimana nilai lebih dari 0,05 sehingga dapat disimpulkan bahwa data berdistribusi normal.

\section{Analisis Korelasi}

Untuk mengetahui hubungan antara efektivitas digital storytelling dengan meningkatkan keterampilan komunikasi, maka akan dilakukan uji korelasi dengan software SPSS 18 sebagai berikut:

Tabel 2.

\begin{tabular}{|ll|r|r|}
\hline \multicolumn{1}{|c|}{ Correlations } & $\begin{array}{c}\text { DIGITALSTORY } \\
\text { TELLING }\end{array}$ & $\begin{array}{c}\text { KETERAMPILAN } \\
\text { KOMUNIKASI }\end{array}$ \\
\hline DIGITALSTORYTELLING & Pearson Correlation & 1 & $.727^{* *}$ \\
& Sig. (2-tailed) & & .000 \\
& $\mathrm{~N}$ & 50 & 50 \\
\hline KETERAMPILANKOMUNIK & Pearson Correlation & $.727^{* *}$ & 1 \\
ASI & Sig. (2-tailed) & .000 & 50 \\
& $\mathrm{~N}$ & 50 & \\
\end{tabular}

${ }^{* *}$. Correlation is significant at the 0.01 level (2-tailed).

Berdasarkan tabel 2 mengenai uji korelasi Pearson, dapat diketahui bahwa nilai koefisien korelasi adalah sebesar 0,727. Artinya, hubungan antara efektivitas digital storytelling dengan meningkatkan keterampilan komunikasi memiliki hubungan yang kuat.

\section{Koefisien Determinasi}

Untuk mengetahui besarnya pengaruh antara penggunaan digital storytelling dalam meningkatkan keterampilan komunikasi, maka dapat ditentukan dengan rumus koefisien determinasi sebagai berikut:

$$
\begin{gathered}
K D=r^{2} \times 100 \% \\
K D=(0,727)^{2} \times 100 \% \\
K D=52,9 \%
\end{gathered}
$$

Hasil koefisien determinasi pada perhitungan adalah sebesar 52.9\%. Hal ini menunjukkan bahwa digital storytelling yang digunakan kanal youtube "Ilmu Komunikasi UNJ" dalam membuat konten memberikan pengaruh sebesar 52,9\% dalam meningkatkan keterampilan komunikasi, sedangkan sisanya 47,1\% merupakan faktor-faktor lain yang tidak diteliti pada penelitian ini.

\section{Analisis Regresi Linier Sederhana}


Analisis regresi linear digunakan untuk mengetahui ada atau tidaknya efektivitas penggunaan digital storytelling dalam meningkatkan keterampilan komunikasi. Data yang didapatkan dari rumus adalah sebagai berikut:

Tabel 3.

ANOVA $^{\mathrm{b}}$

\begin{tabular}{|ll|r|r|r|c|c|}
\hline Model & & Sum of Squares & df & Mean Square & F & Sig. \\
\hline 1 & Regression & 628.635 & 1 & 628.635 & 53.904 & $.000^{\mathrm{a}}$ \\
& Residual & 559.785 & 48 & 11.662 & & \\
Total & 1188.420 & 49 & & & \\
\hline
\end{tabular}

a. Predictors: (Constant), DIGITALSTORYTELLING

b. Dependent Variable: KETERAMPILANKOMUNIKASI

Dari hasil output tersebut, diketahui bahwa nilai F-hitung $=53,904$ dengan tingkat signifikansi sebesar $0,000<0,005$, maka model regresi dapat dipakai untuk memprediksi variabel partisipasi, dengan kata lain ada pengaruh variabel digital storytelling terhadap variabel keterampilan komunikasi.

Maka dari itu, uji hipotesis dapat digunakan untuk melihat besarnya pengaruh variabel efektivitas penggunaan digital storytelling dalam meningkatkan keterampilan komunikasi sebagai berikut:

Tabel 4.

Coefficients $^{\mathrm{a}}$

\begin{tabular}{|c|c|c|c|c|c|c|}
\hline \multirow{2}{*}{\multicolumn{2}{|c|}{ Model }} & \multicolumn{2}{|c|}{ Unstandardized Coefficients } & \multirow{2}{*}{$\begin{array}{c}\text { Standardized } \\
\text { Coefficients } \\
\text { Beta }\end{array}$} & \multirow[b]{2}{*}{$\mathrm{t}$} & \multirow[b]{2}{*}{ Sig. } \\
\hline & & B & Std. Error & & & \\
\hline \multirow[t]{2}{*}{1} & (Constant) & .635 & 3.831 & & .166 & .869 \\
\hline & DIGITALSTORYTELLING & .659 & .090 & .727 & 7.342 & .000 \\
\hline
\end{tabular}

a. Dependent Variable: KETERAMPILANKOMUNIKASI

Berdasarkan hasil output yang dipaparkan dalam tabel 4, dapat diketahui bahwa nilai t-hitung sebesar 7.342. karena t-hitung (7.342) > t-tabel (1,660), maka Ho ditolak. Artinya terdapat efektivitas antara penggunaan digital storytelling dalam meningkatkan keterampilan komunikasi.

\section{E. Simpulan}

Dapat disimpulkan dari hasil penelitian, penggunaan digital storytelling secara keseluruhan terbukti efektif dengan skor persentase $81,42 \%$. Hal ini secara langsung menunjukkan bahwa penggunaan digital storytelling terbukti berhasil digunakan oleh kanal 
youtube "Ilmu Komunikasi UNJ" dalam membuat konten atau menyampaikan materi. Sedangkan keterampilan komunikasi mendapatkan skor persentase $71,35 \%$ yang menunjukkan bahwa konten "Ilmu Komunikasi UNJ" secara tidak langsung mengundang kesadaran tinggi dalam belajar dan meningkatkan keterampilan komunikasi.

Paparan data dari hasil penelitian mengenai penggunaan digital storytelling memiliki pengaruh sebesar 52,9\% dalam meningkatkan keterampilan komunikasi. Sedangkan sisanya $47,1 \%$ dipengaruhi oleh faktor lain yang tidak terdapat dalam penelitian ini. Hubungan yang kuat antara digital storytelling dengan keterampilan komunikasi dibuktikan dengan hasil perhitungan koefisien determinasi sebesar 0,727 menggunakan rumus koefisien determinasi.

\section{Daftar Pustaka}

Ahmadi \& Hermawan. (2013). E-Business \& E-Commerce. Yogyakarta: Andi, hlm. 68 Alexander, B. (2011). The New Digital Storytelling Creating Naratives with New Media. Oxford England: Praeger, hlm. 3

Dalimunthe, H. (2008). Hubungan Antara Persepsi Terhadap Profesionalisme Guru Dengan Keterampilan Komunikasi Pada Guru SMAN 2 Medan. (Skripsi). Universitas Sumatera Utara, Medan, Indonesia.

Drajat, H. \& Purnama, H. (2019). Efektivitas Penggunaan Digital Storytelling Kanal Youtube "Kok Bisa?” Dalam Meningkatkan Minat Belajar. Jurnal Komunikasi Universitas Garut: Hasil Pemikiran dan Penelitian, 6(1): hlm. 382-390.

Heriyana, Wina. (2014). Penerapan Metode Digital Storytelling Pada Keterampilan Menceritakan Tokoh Idola Mata Pelajaran Bahasa Indonesia Siswa Kelas VII di SMP Negeri 11 Kedamean Gresik, Jurnal Mahasiswa Teknologi Pnedidikan, 2(2): hlm. 19

Lambert, Joe. (2010). Digital Storytelling Cookbook. Tersedia dari: https://wrd.as.uky.edu/sites/default/files/cookbook.pdf

Nurudin. (2016). Ilmu Komunikasi Ilmiah dan Populer. Jakarta: PT. Raja Grafindo Persada, hlm. 118

Pengguna Internet di Indonesia. (2019). Tersedia dari:

https://aptika.kominfo.go.id/2019/08/penggunaan-internet-di-indonesia/ [22 Mei 2020].

Sumantri, M.S. (2015). Strategi Pembelajaran: Teori dan Praktik di Tingkat Pendidikan Dasar. Jakarta: PT. Raja Grafindo, hlm. 1

Supriyono, R. (2010). Desain Komunikasi Visual: Teori dan Aplikasi. Yogyakarta: Andi, hlm. 9

Sutama. (2016). Metode Penelitian Pendidikan Kuantitatif, Kualitatif, PTK, dan R\&D. Kartasura: Fairuz Media, hlm. 43 
